\title{
Factors that facilitate multigenerational exchanges in regional locations: a cross- sectional study in Niigata City, Japan
}

Kumiko Morita ${ }^{1 *}$, Minako Kobayashi ${ }^{2}$, Rieko Aoki ${ }^{1}$, Hitomi Nagamine ${ }^{3}$, Harumi Yamamoto ${ }^{1}$, Fumi Ohtake ${ }^{1}$, Mika Hoki ${ }^{1}$, Hiroko Sumita ${ }^{1}$, Kayo Maruyama ${ }^{1}$, Kayoko Mitsuhashi ${ }^{1}$ and Akiko Sasaki ${ }^{1}$

\begin{abstract}
Background: In the process of community building, it is important to create a place for multigenerational exchanges. To promote multigenerational exchanges in regional locations, it is essential to clarify whether such exchanges are related to government infrastructure, regional characteristics, and social capital, and how these exchanges contribute to community building.
\end{abstract}

Methods: A cross-sectional questionnaire study was conducted with representatives from 455 Chiiki no Cha-no-Ma (literal translation "community living room," and hereafter "Cha-no-Ma") in Niigata City, Japan. Responses were received from 405 representatives (response rate: $89.0 \%$ ), and 401 agreed to participate (4 declined). The survey details included basic information (e.g., date each location was established, frequency of meetings, number of caretakers and participants, qualifications of the representative), activities reflecting local culture, a social capital scale, the effects of the Cha-no-Ma implemented by the representative (12 items), challenges for management (16 items), and the implementation of multigenerational exchanges.

Results: Most of the age groups that participated in the Cha-no-Ma were elderly, and multigenerational exchanges took place in 125 locations (31.5\%). Items that had a significant connection to the implementation of multigenerational exchanges were "Frequency of meetings" $(p<0.001)$ and "Activities reflecting local culture" ( $p=$ 0.026). Binomial logistic regression analysis indicated that a high frequency of meetings was associated with the implementation of multigenerational exchanges (Odds ratio $=3.839$ ).

There was a significantly higher ratio of implementation of multigenerational exchanges when the effects were a "connection with the region" ( $p=0.006$ ) and "conversations with different generations" ( $p=0.004)$, and when the challenge was "no support from residents" ( $p=0.002$ ).

(Continued on next page)

\footnotetext{
* Correspondence: morita.phn@tmd.ac.jp

${ }^{1}$ Tokyo Medical and Dental University (TMDU), 1-5-45 Yushima Bunkyo-ku, 113-8519 Tokyo, Japan

Full list of author information is available at the end of the article
}

C C The Author(s). 2021 Open Access This article is licensed under a Creative Commons Attribution 4.0 International License, which permits use, sharing, adaptation, distribution and reproduction in any medium or format, as long as you give appropriate credit to the original author(s) and the source, provide a link to the Creative Commons licence, and indicate if changes were made. The images or other third party material in this article are included in the article's Creative Commons licence, unless indicated otherwise in a credit line to the material. If material is not included in the article's Creative Commons licence and your intended use is not permitted by statutory regulation or exceeds the permitted use, you will need to obtain permission directly from the copyright holder. To view a copy of this licence, visit http://creativecommons.org/licenses/by/4.0/ The Creative Commons Public Domain Dedication waiver (http://creativecommons.org/publicdomain/zero/1.0/) applies to the data made available in this article, unless otherwise stated in a credit line to the data. 


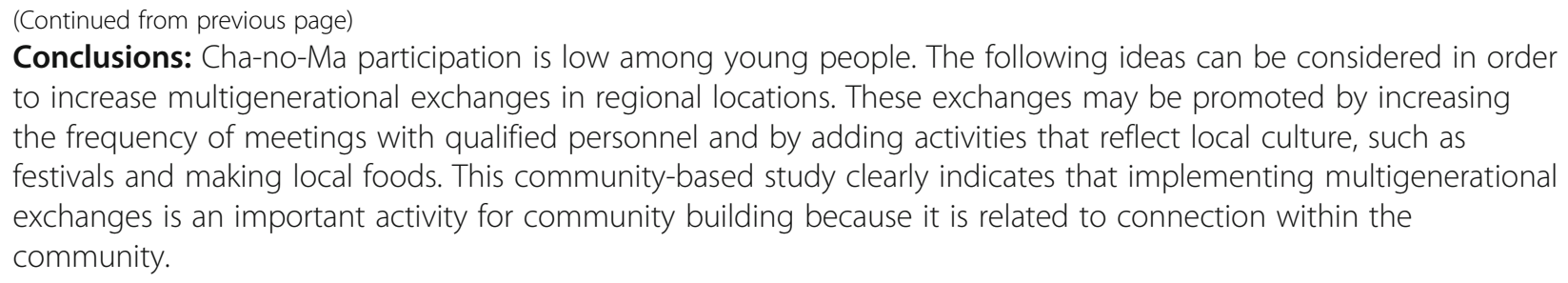

Keywords: Multigenerational exchanges, Community building, Social capital, Community-based study

\section{Background}

Japan is facing the prospect of becoming an aging society due to both the extension of life expectancy and the declining birthrate. The average number of family members is predicted to decrease from 2.33 to 2015 to 2.08 by 2040 , and the number of solitary households is also increasing [1]. To enable older people to live their lives as they wish in a familiar environment, municipalities and prefectures must establish a community-based integrated care system based on regional autonomy and independence [2]. The need for a community-based integrated care system is urgent because the number of family members available to support elder care is increasingly limited. In the process of community building, it is important to create places where people may interact. Over the past several decades, social isolation and loneliness among older adults have posed an increasingly urgent challenge because of the rapidly aging population in Japan. To remedy the situation, many communities have introduced multigenerational programs. Accordingly, attention has been focused on the Chiiki no Cha-no-Ma (hereafter "Cha-no-Ma"), which have been implemented in Niigata City in Niigata Prefecture [3].

Niigata City has a population of approximately 800 , 000, and it is almost $2 \mathrm{~h}$ by bullet train from Tokyo. The proportion of persons aged over 65 years was $29.2 \%$ in 2019. Niigata is famous as a rice-producing area of Japan, but there is a shortage of farmers as many young people have left the region to live in cities. In 1964, the area experienced a magnitude 7.5 earthquake, which caused significant damage. However, inhabitants cooperated and rebuilt the city. Community ties and civil society activities are not only decisive in fostering community resilience against disaster, but also for coordinating relief, rebuilding, and by extension, adapting to perpetual change [4].

"Chiiki no Cha-no-Ma" can be translated literally as "community living room." It is not a religious or political organization, but rather a place where older people and mothers with children in the neighborhood can easily visit and spend a pleasant time with people of different age groups. The phrase "third place" has been defined as "public places that host the regular, voluntary, informal, and happily anticipated gatherings of individuals beyond the realms of home and work" [5]. Cha-no-Ma is one such third place. In 1997, Chano-Ma began with monthly regional exchanges in local community halls. Cha-no-Ma received attention for being locations that, rather than offering special programs, permitted local residents to visit and spend as much time there as they wished. Cha-no-Ma have developed as a form of citizen-led support using meeting places and vacant homes. With cooperation from social welfare councils and the Welfare Division of Niigata City, at least 500 locations were operating in Niigata as of 2018, with the involvement of specialists such as public health nurses, hospital nurses, and occupational therapists. The 2014 revision of the "Guidelines for health activities of public health nurses in the community" [6] included the promotion of self-help and mutual support using social capital (e.g., communitybased trust, social standards, networks, and societyrelated capital), and identified Cha-no-Ma as a base for regional activities by public health nurses.

Furthermore, multigenerational exchange effects are expected as different generations gather at Cha-no-Ma. Multigenerational exchange denotes that members of different generations can be present, feel welcome, and engage in activities [7]. Many of the effects of intergenerational exchanges have been revealed in prior studies that focused on older persons and children [8-13]. Moreover, Cha-no-Ma are expected to foster community regeneration based on the connections created between citizens through intergenerational exchange; studies have assessed their positive effects on increasing social capital (hereafter "SC") [14-17]. SC and health is a multidisciplinary topic, with studies often drawing from theories and concepts in the social, political, and behavioral sciences [18]. Putnam [19] defined SC as the features of social organizations, such as networks, norms, and social trust, that facilitate coordination and cooperation for mutual benefit. Carpiano [20] suggested that SC consists of four main forms: (1) social support, (2) social leverage, (3) informal social control, and (4) neighborhood organization and participation. 
Cha-no-Ma are spaces where people from different generations can socialize and interact rather than be isolated, which ideally produces spontaneous multigenerational exchanges [21]. However, the current situation is that most participants are older people; an important issue, therefore, is how to promote participation by members of younger generations so that multigenerational exchanges can occur in Cha-no-Ma. Implementing multigenerational exchanges in after-school care is expected to promote "learning experiences and knowledge from older persons" and "nurturing respect for older persons." However, talent acquisition (individuals who can act as facilitators of multigenerational exchanges) and location are issues that must be addressed [22]. Nevertheless, while after-school care is a government-sponsored activity, Cha-no-Ma is run by community members. Can a government infrastructure influence the implementation of multigenerational exchanges?

The community-based integrated care system seamlessly provides healthcare, long-term care, preventive care, housing, and livelihood support services so that older people can live independently in their communities. However, this is not a nationwide approach, and it is carried out independently by each region [2]. Depending on the region, there are areas where residents have strong ties with each other, and there are areas where even neighbors rarely meet. Can regional characteristics influence multigenerational exchange? It has been proposed that $\mathrm{SC}$ is strengthened through the activation of civic activity, and that civic activity is promoted if $\mathrm{SC}$ is rich [23]. While the former has been confirmed in previous research, the positive influence of rich SC on multigenerational exchange has not been confirmed. Cha-no-Ma is modeled in many areas and is highly useful in clarifying how multigenerational exchanges that deepen community ties are carried out therein.

Therefore, in this study, we clarified whether government infrastructure, regional characteristics, and SC are related to the implementation of multigenerational exchange in Cha-no-Ma. Further, we clarified their relationship with the effects and challenges of Cha-no-Ma, investigating how the implementation of multigenerational exchange can contribute to community building.

\section{Methods}

\section{Participants}

The study covered 455 Cha-no-Ma locations that were active as of July 2019, of which 405 responded (response rate: $89.0 \%$ ) and 401 agreed to participate (4 declined). The study period was June to October 2019.

\section{Design}

This was a cross-sectional study based on a self-report questionnaire. The distribution of the questionnaires was conducted by Niigata City, which organizes the Cha-no-Ma, and the questionnaires were returned directly to the researchers after completion.

\section{Outcome measures}

The survey included basic information (e.g., date facility was established, frequency of meetings, number of caretakers and participants, qualifications of the representatives), activities reflecting local culture, a social capital scale (hereafter "SC Scale"), the effects of the Cha-noMa being implemented by the representatives (12 items), challenges for management (16 items), and the implementation of multigenerational exchanges. A conceptual overview is shown in Fig. 1.

The SC Scale developed by Kawaharada et al. [24] comprises 20 items, and measures the outcome of community health activities related to the development of SC. Many conventional SC scales measure the status of interactions among individual residents in their areas. In contrast, the scale developed by Kawaharada et al. includes items that measure the situation of the entire area and the relationship with the public health nurse or nutritionist. The representative of the Cha-no-Ma has a close relationship with the area and can likely evaluate the $\mathrm{SC}$ of the entire area, hence the choice to use this scale. The internal validity was confirmed, with a Cronbach's $\alpha$ coefficient of 0.92 . Moreover, this scale permitted analysis of each factor. In this study, three factors were used to examine the residential region from the perspective of the representative, namely, Factor 1: Trust and support of local people (7 items), Factor 3: Affinity with city professions (3 items), and Factor 5: Association with the neighborhood (3 items). Answers for items were provided on a 5-point Likert scale, with response options of "Strongly agree" (5 points), "Agree," "Neither agree nor disagree," "Mostly disagree, and "Disagree" (1 point). A higher score indicates better SC conditions. The items addressing the effects of, for example, regional connections or improvement of physical and cognitive functions and management challenges, such as a deficit in profits of transportation to Cha-no-Ma, were created with reference to prior studies $[22,25]$, with multiple selections allowed.

\section{Operational definitions}

Multigenerational exchange: In this type of exchange, it is assumed that two or more generations interact with one another.

Representatives: They are managers of the Cha-no-Ma and support on-site programming. They are residents rather than city employees, but operate in collaboration with Niigata City through an agreement. Some have 


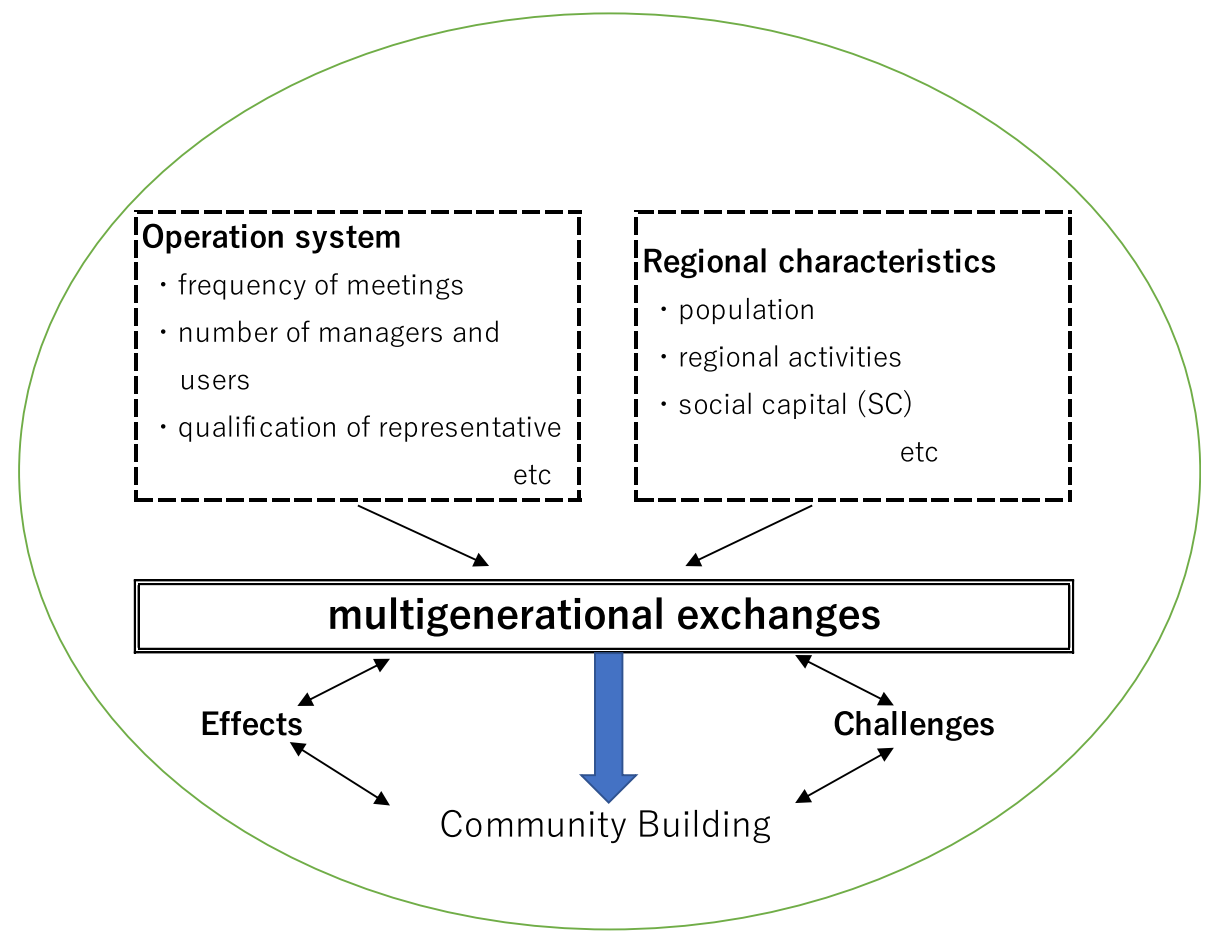

Fig. 1 Brief conceptual overview

specialist qualifications (e.g., nurse), but these qualifications are not a requirement for the role.

Caretakers: They are residents who support the operation of the Cha-no-Ma along with representatives. In many cases, they participate as paid or unpaid volunteers.

Participants: They are people from the community, regardless of age, who attend the Cha-no-Ma programming.

Specialists: Depending on the Cha-no-Ma, specialists such as public health nurses and occupational therapists visit regularly to check participants' health. The specialist is a different from the representative.

\section{Data analysis}

Statistical analysis was performed using IBM SPSS Statistics version 25 for Windows. A $p$-value of $<0.05$ was considered statistically significant. To compare differences in characteristics between two groups, we employed Fisher's exact test and the Mann-Whitney U test. Logistic regression analysis was carried out with the implementation of multigenerational exchanges as the dependent variable and the related factors as independent variables.

\section{Ethics approval and consent to participate}

All participants were informed about this study in writing before it commenced. Consent for participation was assumed based on the return of questionnaires. We received approval from the ethics review board of Tokyo Medical and Dental University (Approval number: M2018-318; approved on April 19, 2019).

\section{Results}

Operational status of cha-no-ma

Table 1 shows the operational status of Cha-no-Ma. More than half of the Cha-no-Ma $(236 ; 66.1 \%)$ were established in 2010 or thereafter. Approximately $90 \%$ of the participants were 75 years of age or older, or between 65 and 74. Multigenerational exchanges were said to take place in 125 locations (31.5\%). Of the 125 cases in which multigenerational exchanges were conducted, $32(30.5 \%)$ occurred with two generations and $73(69.5 \%)$ with 3 or more generations (excluding no answer) (Fig. 2).

\section{Factors related to the implementation of multigenerational exchanges}

Table 2 shows the items significantly associated with implementation of multigenerational exchanges. The ratio of multigenerational exchanges was significantly higher $(p<0.001)$ in groups that met more frequently (once or more per week). Of the 135 specific descriptions of activities reflecting local culture, the main items 
Table 1 Operational status of Cha-no-Ma

\begin{tabular}{|c|c|c|c|}
\hline & & n & $\%$ \\
\hline \multirow[t]{2}{*}{ Frequency of meetings } & Once or more per week & 57 & 14.2 \\
\hline & Once/twice per month & 344 & 85.8 \\
\hline \multirow[t]{3}{*}{ Year established } & Prior to 1999 & 26 & 7.3 \\
\hline & $2000-2009$ & 95 & 26.6 \\
\hline & 2010-2019 & 236 & 66.1 \\
\hline \multirow{8}{*}{$\begin{array}{l}\text { Age groups engaged at Cha-no-Ma: multiple answers per } \\
\text { establishment }\end{array}$} & 75 or above & 357 & 90.6 \\
\hline & $65-74$ & 353 & 89.6 \\
\hline & $40-64$ & 145 & 36.8 \\
\hline & $18-39$ & 36 & 9.1 \\
\hline & Senior high school student & 6 & 1.5 \\
\hline & Junior high school student & 15 & 3.8 \\
\hline & Elementary school student & 59 & 15.0 \\
\hline & Pre-school-age child & 28 & 7.1 \\
\hline Multigenerational exchanges & Yes & 125 & 31.5 \\
\hline \multicolumn{2}{|l|}{ Average number of participants per day } & \multicolumn{2}{|l|}{$18.0 \pm 8.3$} \\
\hline \multicolumn{2}{|l|}{ Average number of caretakers } & \multicolumn{2}{|l|}{$4.1 \pm 3.1$} \\
\hline \multicolumn{2}{|l|}{ Average age of representative } & \multicolumn{2}{|l|}{$72.3 \pm 7.1$} \\
\hline
\end{tabular}

were related to food (49 items), such as "making local foods," followed by items related to "festivals" (36 items).

Table 3 shows the items that differed significantly by Mann-Whitney U Test. The median number of caretakers was 4.5 in Cha-no-Ma in which multigenerational exchanges were implemented, and 3.5 otherwise $(p=$ 0.003). The effect size was 0.22 to 0.48 .

Among the relevant factors clarified in Tables 2 and 3, a binomial logistic regression analysis was conducted to confirm the extent and the influence of multigenerational exchanges (Table 4). With consideration of collinearity, only the total SC scale score was used for the items that were significant in the univariate analysis. Among the other items, there were no correlations of $r>0.2$. A high frequency of meetings was associated with the implementation of multigenerational exchanges (Odds ratio, $\mathrm{OR}=3.839$ ).

\section{Relationship between the effects of cha-no-ma and the implementation of multigenerational exchanges}

There were associations between the effects of Cha-no$\mathrm{Ma}$ and implementation of multigenerational exchanges for 2 of 12 items (Table 5). Implementation of multigenerational exchanges was significantly more likely given a "connection with the region" $(p=0.006)$ and

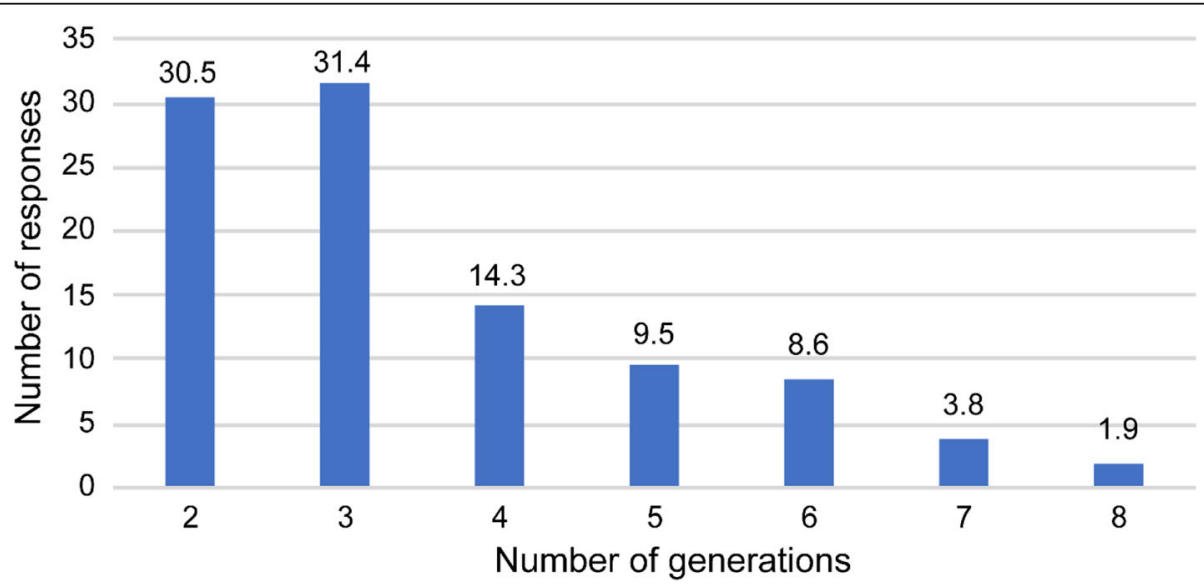

Fig. 2 Number of generations interacting 
Table 2 Items significantly associated with implementation of multigenerational exchanges

\begin{tabular}{|c|c|c|c|c|c|}
\hline \multirow[b]{2}{*}{ Item } & & \multirow[b]{2}{*}{$\begin{array}{l}\text { Number of responses: } \\
\text { excluding no answer }\end{array}$} & \multicolumn{3}{|c|}{$\begin{array}{l}\text { Multigenerational } \\
\text { exchanges } \\
\text { present }\end{array}$} \\
\hline & & & $\bar{n}$ & $\%$ & $p$-value \\
\hline \multirow[t]{2}{*}{ Frequency of meetings } & $\begin{array}{l}\text { High (once or more } \\
\text { per week) }\end{array}$ & 56 & 32 & 57.1 & $<0.001$ \\
\hline & $\begin{array}{l}\text { Low (once/twice per } \\
\text { month) }\end{array}$ & 341 & 93 & 27.3 & \\
\hline \multirow[t]{2}{*}{ Specialist qualification of representative (e.g., nurse) } & Yes & 78 & 32 & 41.0 & 0.026 \\
\hline & No & 279 & 77 & 27.6 & \\
\hline \multirow{2}{*}{$\begin{array}{l}\text { Activities reflecting local culture (e.g., making local foods, } \\
\text { festivals, seasonal events) }\end{array}$} & Yes & 147 & 60 & $(40.8)$ & 0.001 \\
\hline & No & 217 & 53 & $(24.4)$ & \\
\hline
\end{tabular}

${ }^{a}$ Fisher's exact test

"conversations with different generations" $(p=0.004)$. Next, the analysis was conducted only in places where multigenerational exchanges were carried out. When comparing the two-generation exchange with the threegeneration or more (3+) exchange, the $3+$ generation exchange showed significantly greater "improvement of cognitive function," "interest in health," "increased smiling," and "conversations with different generations" $(p<0.05$; Table 5$)$.

\section{Relationship between challenges of cha-no-ma and the implementation of multigenerational exchanges}

There were associations between the implementation of multigenerational exchanges and the challenges of implementation for 4 of 16 items (Table 6). Implementation of multigenerational exchanges was significantly more likely when facing the challenge of "no support from residents" ( $p=0.002)$.

Table 3 Items that differed significantly according to whether multigenerational exchanges were implemented

\begin{tabular}{llllll}
\hline & ME & Average rank & Median & $\boldsymbol{p}^{\text {-value }}{ }^{\mathbf{a}}$ & $\boldsymbol{d}^{\mathbf{b}}$ \\
\hline Number of caretakers & yes & 221.44 & 4.50 & 0.003 & 0.26 \\
& no & 185.10 & 3.00 & & \\
SC score (Factor I) & yes & 209.77 & 27.00 & 0.003 & 0.31 \\
& no & 174.14 & 26.00 & & \\
SC score (Factor V) & yes & 209.49 & 12.00 & 0.032 & 0.22 \\
& no & 183.83 & 12.00 & & \\
Total SC score & yes & 202.12 & 49.00 & 0.015 & 0.48 \\
& no & 173.32 & 47.00 & & \\
\hline
\end{tabular}

${ }^{a}$ Mann-Whitney $U$ test

${ }^{b}$ Effect size: This was calculated using the method developed by Cohen (1988)

Abbreviations: $M E$ multigenerational exchange; SC social capital

\section{Discussion}

Factors related to the implementation of multigenerational exchanges

As shown in Table 4, higher frequency of holding meetings was the primary variable associated with implementation of multigenerational exchanges. It is likely easier for children and working people to arrange their schedules if meetings are held frequently. Morita et al. $[22,26]$ also reported that the implementation and continuation of exchanges between generations are affected by schedule adjustments. Furthermore, the amount of funding from the government in Niigata City depends on the frequency of meetings held. While locations that hold meetings once or more per week receive up to 20 , 000 yen $(\sim 190$ US $\$ / 160$ euros) per month as well as an initial payment of 200,000 yen $(\sim 1,900$ US $\$ / 1,600$ euros), those locations that hold meetings once or twice per month receive a payment of only up to 2, 500 yen $(\sim 25$ US\$/20 euros) per month [27]. Pain et al. [28] suggested that "More direct funding is needed for intergenerational programs" and "Financial support and social policy support are critical for the long-term sustainability of intergenerational programs" $[29,30]$. It was assumed that the budget would have the same connection in the current study; groups that meet once or more per week and receive a larger subsidy are likely to have better environments for implementing multigenerational exchanges.

Even if there is a desire to implement multigenerational exchanges, this cannot be enacted if there is a lack of applicable knowledge. In this study, many of the representatives with specialist qualifications were nurses, doctors, childcare workers, nutritionists, or counselors. The success of intergenerational programs is determined by the presence of a skilled healthcare professional and a qualified recreation therapist [31]. The most significant subcomponents regarding a facilitator's skills include being knowledgeable about different generations (e.g., children, 
Table 4 Factors related to multigenerational exchanges (multivariate analysis)

\begin{tabular}{|c|c|c|c|c|c|c|c|}
\hline \multirow{2}{*}{ 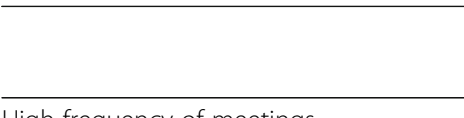 } & \multirow[t]{2}{*}{ B } & \multirow[t]{2}{*}{ SE } & \multirow[t]{2}{*}{ Wald } & \multirow[t]{2}{*}{$p$-value } & \multirow[t]{2}{*}{ OR } & \multicolumn{2}{|c|}{ OR $95 \%$ confidence interval } \\
\hline & & & & & & Minimum & Maximum \\
\hline High frequency of meetings & 1.345 & 0.337 & 15.982 & $<0.001$ & 3.839 & 1.985 & 7.425 \\
\hline No. of caretakers & -0.074 & 0.047 & 2.513 & 0.113 & 0.929 & 0.848 & 1.018 \\
\hline Specialist qualification ${ }^{a}$ of representative & 0.785 & 0.297 & 6.998 & 0.008 & 2.193 & 1.226 & 3.925 \\
\hline SC scale total & -0.030 & 0.019 & 2.669 & 0.102 & 0.970 & 0.936 & 1.006 \\
\hline Activities reflecting local culture & 0.585 & 0.267 & 4.806 & 0.028 & 1.794 & 1.064 & 3.027 \\
\hline Constant & 0.515 & 0.993 & 0.269 & 0.604 & 1.674 & & \\
\hline
\end{tabular}

${ }^{a}$ Specialist qualifications included nurses, doctors, childcare workers, nutritionists, counselors, teachers, etc. Binomial logistic regression analysis: Forced entry method; Model $\mathrm{X}^{2}, p<0.001$, Hosmer-Lemeshow test, $p=0.572$.

Abbreviation: $O R$ odds ratio; SE standard error

Table 5 Relationship between the effects of Cha-no-Ma participation and multigenerational exchanges

\begin{tabular}{|c|c|c|c|c|c|c|c|c|c|}
\hline \multirow[b]{3}{*}{ Effect of Cha-no-Ma } & & \multicolumn{4}{|l|}{$\begin{array}{l}\text { All data } \\
\text { (excluding no answer) }\end{array}$} & \multicolumn{4}{|c|}{$\begin{array}{l}\text { Only those implementing } \\
\text { multigenerational exchange } \\
\text { (excluding no answer) }\end{array}$} \\
\hline & & \multirow[b]{2}{*}{ Number of responses } & \multicolumn{3}{|c|}{$\begin{array}{l}\text { Multigenerational } \\
\text { exchanges found }\end{array}$} & \multirow[b]{2}{*}{ Number of responses } & \multicolumn{3}{|c|}{$\begin{array}{l}3+\text { generation } \\
\text { exchanges found }\end{array}$} \\
\hline & & & $\mathrm{n}$ & $\%$ & $p$-value ${ }^{a}$ & & $\mathrm{n}$ & $\%$ & $p$-value ${ }^{a}$ \\
\hline \multirow[t]{2}{*}{ Increased smiling } & Effect & 314 & 96 & 30.6 & 0.500 & 79 & 59 & 74.7 & 0.045 \\
\hline & No effect & 80 & 28 & 35.0 & & 26 & 14 & 53.8 & \\
\hline \multirow[t]{2}{*}{ Interest in health } & Effect & 275 & 88 & 32.0 & 0.813 & 74 & 58 & 78.4 & 0.005 \\
\hline & No effect & 118 & 36 & 30.3 & & 31 & 15 & 48.4 & \\
\hline \multirow[t]{2}{*}{ Connection with the region } & Effect & 264 & 95 & 36.0 & 0.006 & 80 & 55 & 68.8 & 0.809 \\
\hline & No effect & 130 & 29 & 22.3 & & 25 & 18 & 72.0 & \\
\hline \multirow[t]{2}{*}{ Prevention of isolation } & Effect & 252 & 80 & 31.7 & 0.910 & 67 & 50 & 74.6 & 0.185 \\
\hline & No effect & 142 & 44 & 31.0 & & 38 & 23 & 60.5 & \\
\hline \multirow[t]{2}{*}{ Conversations with same generations } & Effect & 232 & 77 & 33.2 & 0.442 & 67 & 47 & 70.1 & 1.000 \\
\hline & No effect & 162 & 47 & 29.0 & & 38 & 26 & 68.4 & \\
\hline \multirow[t]{2}{*}{ Watch over } & Effect & 194 & 70 & 36.1 & 0.440 & 59 & 45 & 76.3 & 0.134 \\
\hline & No effect & 200 & 54 & 27.0 & & 46 & 28 & 60.9 & \\
\hline \multirow[t]{2}{*}{ Improved physical function } & Effect & 133 & 46 & 34.6 & 0.360 & 37 & 29 & 78.4 & 0.185 \\
\hline & No effect & 261 & 78 & 29.9 & & 68 & 44 & 69.7 & \\
\hline \multirow[t]{2}{*}{ Attend alone } & Effect & 132 & 47 & 35.6 & 0.250 & 37 & 26 & 70.3 & 1.000 \\
\hline & No effect & 262 & 77 & 29.4 & & 68 & 47 & 69.1 & \\
\hline \multirow[t]{2}{*}{ Improved cognitive function } & Effect & 99 & 27 & 27.3 & 0.319 & 21 & 19 & 90.5 & 0.019 \\
\hline & No effect & 295 & 97 & 32.9 & & 84 & 54 & 64.3 & \\
\hline \multirow[t]{2}{*}{ Conversations with different generations } & Effect & 96 & 42 & 43.8 & 0.004 & 39 & 33 & 84.6 & 0.015 \\
\hline & No effect & 298 & 82 & 27.5 & & 66 & 40 & 60.6 & \\
\hline \multirow[t]{2}{*}{ Meal support } & Effect & 57 & 18 & 31.6 & 1.000 & 14 & 9 & 64.3 & 0.756 \\
\hline & No effect & 337 & 106 & 31.5 & & 91 & 64 & 70.3 & \\
\hline \multirow[t]{2}{*}{ Read newspapers or magazines } & Effect & 9 & 3 & 33.3 & 1.000 & 3 & 3 & 100.0 & 0.551 \\
\hline & No effect & 385 & 121 & 31.4 & & 102 & 70 & 68.6 & \\
\hline
\end{tabular}

${ }^{\text {a }}$ Fisher's exact test 
Table 6 Relationship between the challenges of Cha-no-Ma and implementation of multigenerational exchanges

\begin{tabular}{|c|c|c|c|c|c|}
\hline \multirow{2}{*}{ Challenge } & & \multirow[b]{2}{*}{ Number of responses: excluding no answer } & \multicolumn{3}{|c|}{ Multigenerational exchanges found } \\
\hline & & & $\bar{n}$ & $\%$ & $p$-value ${ }^{a}$ \\
\hline \multirow[t]{2}{*}{ Fixed participants } & Yes & 227 & 67 & 29.5 & 0.372 \\
\hline & No & 158 & 54 & 34.2 & \\
\hline \multirow[t]{2}{*}{ Fostering successors } & Yes & 198 & 68 & 34.3 & 0.228 \\
\hline & No & 187 & 53 & 28.3 & \\
\hline \multirow[t]{2}{*}{ Participants do not increase } & Yes & 196 & 58 & 29.6 & 0.444 \\
\hline & No & 189 & 63 & 33.3 & \\
\hline \multirow[t]{2}{*}{ Expected age group does not come } & Yes & 152 & 55 & 36.2 & 0.116 \\
\hline & No & 233 & 66 & 28.3 & \\
\hline \multirow[t]{2}{*}{ Securing caretakers } & Yes & 136 & 47 & 34.6 & 0.359 \\
\hline & No & 249 & 74 & 29.7 & \\
\hline \multirow[t]{2}{*}{ Difficult to enroll new participants } & Yes & 99 & 37 & 37.4 & 0.167 \\
\hline & No & 286 & 84 & 29.4 & \\
\hline \multirow[t]{2}{*}{ Lack of operational know-how } & Yes & 46 & 17 & 37.0 & 0.401 \\
\hline & No & 339 & 104 & 30.7 & \\
\hline \multirow[t]{2}{*}{ No challenges } & Yes & 33 & 10 & 30.3 & 1.000 \\
\hline & No & 352 & 111 & 31.5 & \\
\hline \multirow[t]{2}{*}{ Forming networks with other managers } & Yes & 25 & 13 & 52.0 & 0.027 \\
\hline & No & 360 & 108 & 30.0 & \\
\hline \multirow[t]{2}{*}{ Participant relationships } & Yes & 25 & 10 & 40.0 & 0.375 \\
\hline & No & 360 & 111 & 30.8 & \\
\hline \multirow[t]{2}{*}{ Not well known } & Yes & 24 & 8 & 33.3 & 0.823 \\
\hline & No & 361 & 113 & 31.3 & \\
\hline \multirow[t]{2}{*}{ Poor transportation access } & Yes & 22 & 12 & 54.5 & 0.030 \\
\hline & No & 363 & 109 & 30.0 & \\
\hline \multirow[t]{2}{*}{ No support from local residents } & Yes & 20 & 13 & 65.0 & 0.002 \\
\hline & No & 365 & 108 & 29.6 & \\
\hline \multirow[t]{2}{*}{ Deficit in profits } & Yes & 19 & 11 & 57.9 & 0.020 \\
\hline & No & 366 & 110 & 30.1 & \\
\hline \multirow[t]{2}{*}{ Difficult to secure an exchange place } & Yes & 10 & 3 & 30.0 & 1.000 \\
\hline & No & 375 & 118 & 31.5 & \\
\hline \multirow[t]{2}{*}{ The effect of the activity is small or unclear } & Yes & 8 & 3 & 37.5 & 0.710 \\
\hline & No & 377 & 118 & 31.3 & \\
\hline
\end{tabular}

${ }^{a}$ Fisher's exact test

youth, and older persons) and having attended formal training on intergenerational program management [32]. Considerable current research in the field examines the importance of knowledge and behaviors of persons who implement the multigenerational programming [33, 34]. As shown in these reports, a facilitator should be present when multigenerational exchanges are implemented. However, because of the current lack of personnel [22, 35], representatives' specialist qualifications affect the implementation of multigenerational exchanges. For example, if a representative has a nursing qualification, it will be useful for considering health.
Several activities reflected local culture, such as cooking together using local foods. Exchanges that incorporated the theme of food were well received by all generations. Indeed, a prior report indicated that "The food-based activities worked well in bringing the groups together" [36]. Furthermore, multigenerational exchanges occurred through festivals based in the region. Festivals are tools of community gathering, intergenerational communication, and transmission of knowledge to the younger generations [37]. Food and festivals can be used to plan exchanges between generations. 
It was expected that those Cha-no-Ma with higher SC would have more multigenerational exchanges, but no such significance was found by multivariate analysis. The effect size of SC was 0.48 in Table 3, and the value of the effect size in a two-group test of mean differences is estimated at 0.50 for medium effects [38]. Hence, increasing the number of respondents may be significant in multivariate analysis. Since SC is becoming diluted in society, the operational system may have greater impact than SC on the implementation of multigenerational exchanges. That is, it is possible to carry out multigenerational exchanges by establishing an operational system even in areas where SC is not established.

\section{Effects of multigenerational exchanges}

In this study, those who implemented multigenerational exchanges reported an effect of "connection with the region." The effect was more pronounced in multigenerational exchanges than in two-generation exchanges. Multigenerational exchanges provide insight into intergenerational diversity and may foster problem solving for individuals, families, and communities. Exchanges between generations had the same effects as reported in prior studies, namely a decrease in the risk of social isolation [7, 39] and an expansion of social networks [40-42]. Furthermore, according to the 2019 Annual Report on the Aging Society [43], most persons aged 60 or over stated that "support to and from neighbors" was necessary to continue living happily in the region where they currently reside $(55.9 \%)$. Considering the different types of cohabitation, there was a higher ratio of two- or three-generation households living with their parents than single-person households or married couples, which shows not only that older persons require support within their region, but also that families with children and even grandchildren feel that such support is necessary. Community building requires the creation of connections between residents and with the region [44], and the multigenerational exchanges conducted at Cha-noMa can be considered useful in this regard.

The implementation of multigenerational exchanges also increases conversations among different generations, as revealed in prior studies [41]. In terms of exchange methods, interactive programs increase the conversation frequency [8]. Conversations among different generations increase the knowledge level of each party more than interactions within the same generation [45]. Conversation may prevent cognitive deterioration among older persons $[34,46]$, improve attitudes toward older people $[11,12,31,47-51]$, and lead to the transmission of knowledge to children [22, 45]. Furthermore, communication is an important factor in SC [17]; communication at Cha-no-Ma connects people so that conversations arise naturally in locations other than
Cha-no-Ma. This may promote residents' safety by preventing crime through observing surroundings and communicating with each other.

\section{Challenges posed by the implementation of multigenerational exchanges}

While the implementation of multigenerational exchanges was found to have positive outcomes, it was also clarified that such exchanges posed challenges. In the 2018 survey of "Generations United," challenges were reported regarding demonstrating the impact of intergenerational programs (63\%), funding intergenerational programming $(60 \%)$, and ensuring accessibility of spaces for all participants (48\%) [52]. Schemes such as enhancing programs for the provision of meals and the planning of festivals are required to implement multigenerational exchanges, and they involve a large budget. Therefore, it is important to secure a suitable budget [28-30]. Regarding the problem of transport access, it may be necessary to appeal to the city to introduce transportation services. A solution to the challenge of "no support from residents" may be found by proactively sharing information. The same is true for "forming networks with other managers," which was also cited as a challenge. According to Ayala et al. [53], there is a need to network, collaborate, and/or partner with other organizations. In Niigata City, a "Cha-no-Ma School" is held every year to train the personnel who manage regional Cha-no-Ma [54]. Additionally, examples of activities are compiled [55] and published on the city website. It is expected that the network of representatives will expand in the future.

\section{Study limitations}

This survey was limited to Cha-no-Ma implemented in Niigata City; therefore, the results may not apply to other regions or countries. It is necessary to study the effects and challenges of implementing multigenerational exchanges in other regions, considering the characteristics, environment, and culture of each region. While this was a cross-sectional, quantitative study, it may be possible to gain more detailed information by conducting a qualitative study.

\section{Conclusions}

Multigenerational exchange in a regional location could be promoted by increasing the frequency of meetings with personnel holding qualifications in areas such as healthcare, childcare, or education. Further, it would be effective to use activities that reflect local culture, such as making local foods and organizing festivals. It is necessary to establish programs that interest participants. Future challenges include cooperating with the government to secure financial resources and 
transportation access. Actively disseminating case studies will help residents to understand and build networks collaboratively with other operators. It is clear from this community-based study that the implementation of multigenerational exchanges is an important activity for community building because it is related to an increase in communication among generations and connection within the community.

\section{Abbreviations}

SC: Social capital; ME: Multigenerational exchange; OR: Odds ratio;

SE: Standard error

\section{Acknowledgements}

The authors would like to thank the representatives of Chiiki no Cha-no-Ma the staff of Niigata City, and the Social Welfare Councils who took part in the study. The authors thank Crimson Interactive Pvt., Ltd. (Ulatus; www.ulatus.jp) for their assistance with manuscript translation and editing.

\section{Authors' contributions}

KM contributed to the design, implementation, data collection, data analyses, and writing of the manuscript. MK and RA contributed to critically refining the article. $\mathrm{HN}, \mathrm{HY}, \mathrm{FO}, \mathrm{MH}, \mathrm{HS}, \mathrm{KMa}$, $\mathrm{KMi}$, and $\mathrm{AS}$ were involved in conducting the study. All authors read and approved the final manuscript.

\section{Funding}

This work was supported by JSPS KAKENHI (Grant Number: 17K01817). The funding body had no role in the design of the study; the collection, analysis, and interpretation of data; or the writing of the manuscript.

\section{Availability of data and materials}

The data sets used and/or analyzed during the current study can be made available by the corresponding author on reasonable request.

\section{Declarations}

Authors' information (optional)

Not applicable.

\section{Ethics approval and consent to participate}

All participants were informed about this study in writing before the study began. Consent for participation was assumed by return of questionnaires. We received approval from the Ethics Review Board of the Faculty of Medicine at Tokyo Medical and Dental University (Approval number: M2018318; approved on April 19, 2019).

\section{Consent for publication}

Not applicable.

\section{Competing interests}

No competing interests to declare.

\section{Author details}

${ }^{1} T o k y o$ Medical and Dental University (TMDU), 1-5-45 Yushima Bunkyo-ku, 113-8519 Tokyo, Japan. ${ }^{2}$ Heisei College of Health Sciences, Gifu, Japan.

${ }^{3}$ Wayo Women's University, Chiba, Japan.

\section{Received: 16 November 2020 Accepted: 19 March 2021}

Published online: 25 March 2021

\section{References}

1. National Institute of Population and Social Security Research. Future estimation of the number of Japanese households. 2018. http://www.ipss. go.jp/pp-ajsetai/j/HPRJ2018/hprj2018_gaiyo_20180117.pdf. Accessed 4 Sep 2020.

2. Ministry of Health, Labour and Welfare. Establishing the community-based integrated care system. 2018. https://www.mhlw.go.jp/english/policy/carewelfare/care-welfare-elderly/dl/establish_e.pdf. Accessed 4 Sep 2020.
3. Watanabe T. A study on expanding citizen participation in Niigata Prefecture through community living rooms. Niigata J Health Welf. 2008;8: 12-26.

4. Dimmer C, Jan L. Mapping social innovation and strengthening community resilience: bottom-up recovery initiatives and community spaces in postdisaster Ishinomaki, Japan. 2014. https://www.researchgate.net/profile/ Christian_Dimmer/publication/303878031_Mapping_Social_Innovation_a nd_Strengthening_Community_Resilience_Bottom-up_Recovery_Initia tives_and_Community_Spaces_in_Post-Disaster_Ishinomaki_Japan/links/ 575a177608aed884620b2e83/Mapping-Social-Innovation-andStrengthening-Community-Resilience-Bottom-up-Recovery-Initiatives-andCommunity-Spaces-in-Post-Disaster-Ishinomaki-Japan.pdf. Accessed 18 Dec 2020.

5. Oldenburg R. The great good place: cafes, coffee shops, bookstores, bars, hair salons, and other hangouts at the heart of a community. New York: Marlowe; 1999.

6. Ministry of Health, Labour and Welfare. Guidelines for health activities of public health nurses in the community. 2013. https://www.mhlw.go.jp/web/ t_doc?datald=00tb9310\&dataType=1\&pageNo=1. Accessed 4 Sep 2020.

7. Kaplan M, Sanchez M, Hoffman J. Intergenerational pathways to a sustainable society. New York: Springer; 2017.

8. Morita K, Kobayashi M. Interactive programs with preschool children bring smiles and conversation to older adults: time-sampling study. BMC Geriatr. 2013;13:111. https://doi.org/10.1186/1471-2318-13-111.

9. Giraudeau C, Bailly N. Intergenerational programs: what can school-age children and older people expect from them? A systematic review. Eur Ageing. 2019;16:363-76. https://doi.org/10.1007/s10433-018-00497-4.

10. Mosor E, Waldherr K, Kjeken I, Omara M, Ritschl V, Pinter-Theiss V, et al. An intergenerational program based on psycho-motor activity promotes wellbeing and interaction between preschool children and older adults: results of a process and outcome evaluation study in Austria. BMC Public Health. 2019;19:254. https://doi.org/10.1186/s12889-019-6572-0.

11. Chao M. A study on the effects of children's attitude toward elder by intergenerational programs. Int J Inf Educ Technol. 2019;9:898-903. https:// doi.org/10.18178/ijiet.2019.9.12.1324.

12. Femia EE, Zarit SH, Blair C, Jarrott SE, Bruno K. Intergenerational preschool experiences and the young child: potential benefits to development. Early Child Res Q. 2008;23:272-87. https://doi.org/10.1016/j.ecresq.2007.05.001.

13. Janke MC, Purnell I, Watts C, Shores K. Associations between engagement types, outcome behaviors, and quality of life for adults with dementia participating in intergenerational programs. Ther Recreat J. 2019;53:132-48. https://doi.org/10.18666/TRJ-2019-V53-12-9647.

14. de Souza EM, Grundy E. Intergenerational interaction, social capital and health: results from a randomised controlled trial in Brazil. Soc Sci Med. 2007;65:1397-409. https://doi.org/10.1016/j.socscimed.2007.05.022.

15. Murayama Y, Murayama H, Hasebe M, Yamaguchi J, Fujiwara $Y$. The impact of intergenerational programs on social capital in Japan: a randomized population-based cross-sectional study. BMC Public Health. 2019;19:156. https://doi.org/10.1186/s12889-019-6480-3.

16. O'Connor JP, Alfrey L, Hall C, Burke G. Intergenerational understandings of personal, social and community assets for health. Health Place. 2019;57:21827. https://doi.org/10.1016/j.healthplace.2019.05.004.

17. Boström A. Intergenerational learning and social capital. In: Schmidt-Hertha $B$, Krašovec SJ, Formosa M, editors. Learning across generations in Europe: contemporary issues in older adult education. Leiden: Brill Sense; 2014. pp. 191-201.

18. Moore S, Kawachi I. Twenty years of social capital and health research: a glossary. J Epidemiol Community Health. 2017;71;513-7. https://doi.org/1 0.1136/jech-2016-208313.

19. Putnam RD. Bowling alone: America's declining social capital.J Democracy. 1995;6;65-78. https://doi.org/10.1353/jod.1995.0002.

20. Carpiano RM. Toward a neighborhood resource-based theory of social capital for health: can Bourdieu and sociology help? Soc Sci Med. 2006;62; 165 - 75. https://doi.org/10.1016/j.socscimed.2005.05.020.

21. Jinnouchi Y, Kikuchi W. A study on possibility and problem of multigenerational interchange place regarding the integrated comprehensive care system. Bull Facul Educ Utsunomiya Univ. 2018;1:235-52.

22. Morita K, Aoki R, Kobayashi M, Yamamoto H, Lyu X, Nagamine H, et al. Current situation of the intergenerational programs with the elderly at afterschool care of schoolchildren on the nationwide survey in Japan. J Jpn Soc Intergenerational Stud. 2017;6:27-36. 
23. Ministry of Health, Labour and Welfare. Social Capital. 2003. https://www mhlw.go.jp/stf/shingi/2r98520000011w0l-att/2r98520000011w95.pdf. Accessed 4 Sep 2020.

24. Kawaharada M, Honda H, Tanaka R, Shindo Y. Development of a social capital scale for use in the field of local public health activities. Jpn J Public Health Nurs. 2017;6:132-40. https://doi.org/10.15078/jjphn.6.2_132.

25. Murayama Y. Adult generativity for the socialization of children: exchanges between aged persons and children in Japanese local communities. J Pol Sci Sociol. 2010;12:85-102.

26. Morita K, Aoki R, Kobayashi M, Yamamoto H, Lyu X, Nagamine $H$, et al. Challenges of practice in intergenerational programs with the elderly at after-school care of schoolchildren: analysis of the consciousness of afterschool care staffs by M-GTA. J Jpn Soc Intergenerational Stud. 2015;5:11-20.

27. Niigata City. Subsidy for 'Chiiki no cha no ma'. 2020. https://www.city.niiga ta.lg.jp/smph/iryo/korei/chiikihokatsucare/tiikinocyanomajosei.html. Accessed 4 Sep 2020.

28. Pain R. Intergenerational relations and practice in the development of sustainable communities. 2005. https://lemosandcrane.co.uk/resources/ ICRRDS\%20intergenerationalrelations.pdf. Accessed 4 Sep 2020.

29. Golenko X, Radford K, Fitzgerald JA, Vecchio N, Cartmel J, Harris N. Uniting generations: a research protocol examining the impacts of an intergenerational learning program on participants and organisations. Australas J Ageing. 2020;39:e425-35. https://doi.org/10.1111/ajag.12761.

30. Buffel T, De Backer F, Peeters J, Phillipson C, Reina VR, Kindekens A, et al. Promoting sustainable communities through intergenerational practice. Procedia Soc Behav Sci. 2014;116:1785-91. https://doi.org/10.1016/j.sbspro.2 014.01.472.

31. Caspar S, Davis E, McNeill DMJ, Kellett P. Intergenerational programs: breaking down ageist barriers and improving youth experiences. Ther Recreat J. 2019;53:149-64. https://doi.org/10.18666/TRJ-2019-V53-I2-9126.

32. Azevedo C, Sánchez M. Pathways to sustainable intergenerational programs: lessons learned from Portugal. Sustainability. 2019;11:6626. https://doi.org/1 $0.3390 /$ su11236626.

33. Jarrott SE, Stremmel AJ, Naar JJ. Practice that transforms intergenerational programs: a model of theory- and evidence informed principles. J Intergener Relatsh. 2019;17:488-504. https://doi.org/10.1080/15350770.201 9.1579154.

34. Gerritzen EV, Hull MJ, Verbeek H, Smith AE, de Boer B. Successful elements of intergenerational dementia programs: a scoping review. J Intergener Relatsh. 2020;18:214-45. https://doi.org/10.1080/15350770.2019.1670770.

35. Morita K, Kobayashi M. Surveys on the current status of intergenerational exchanges with elementary school children at adult day care centers in Tokyo. J Jpn Soc Intergenerational Stud. 2012;2:41-7.

36. Jones M, Ismail S. Discovering intergenerational connections through food Centre for Public Health and Wellbeing, UWE Bristol. 2019. https://www. foodforlife.org.uk/ /media/files/better\%20care/evaluation/04-uwe-fflbc-leicscare-homes.pdf. Accessed 4 Sep 2020.

37. Owusu-Frempong Y. Afrocentricity, the Adae festival of the Akan, African American festivals, and intergenerational communication. J Black Stud. 2005; 35:730-50. https://doi.org/10.1177/0021934704268575.

38. Cohen J. Statistical power analysis for the behavioral sciences. 2nd ed. Burlington: Elsevier Science; 2013.

39. Murayama $Y$, Ohba H, Yasunaga M, Nonaka $K$, Takeuchi $R$, Nishi $M$, et al. The effect of intergenerational programs on the mental health of elderly adults. Aging Ment Health. 2015;19:306-14. https://doi.org/10.1080/13607863.2014. 933309

40. Biggs MJG, Knox KS. Lessons learned from an intergenerational volunteer program: a case study of a shared-site model. J Intergener Relatsh. 2014;12: 54-68. https://doi.org/10.1080/15350770.2014.869981

41. Fujiwara Y, Sakuma N, Ohba H, Nishi M, Lee S, Watanabe N, et al. REPRINTS: effects of an intergenerational health promotion program for older adults in Japan. J Intergener Relatsh. 2009;7:17-39. https://doi.org/10.1080/153 50770802628901.

42. Varma VR, Carlson MC, Parisi JM, Tanner EK, McGill S, Fried LP, et al. Experience Corps Baltimore: exploring the stressors and rewards of highintensity civic engagement. Gerontologist. 2015;55:1038-49. https://doi. org/10.1093/geront/gnu011.

43. Cabinet Office. Annual report on the ageing society. 2019. https://www8.ca o.go.jp/kourei/english/annualreport/2019/pdf/2019.pdf. Accessed 4 Sep 2020
44. MacCallum J, Palmer D, Wright P, Cumming-Potvin W, Northcote J, Booker $M$, et al. Community building through intergenerational exchange programs. Melbourne: National Youth Affairs Research Scheme; 2006. p. 36.

45. Newman S, Hatton-Yeo A. Intergenerational learning and the contributions of older people. Ageing Horiz. 2008;8:31-9.

46. Kuiper JS, Zuidersma M, Oude Voshaar RC, Zuidema SU, van den Heuvel ER, Stolk RP, et al. Social relationships and risk of dementia: a systematic review and meta-analysis of longitudinal cohort studies. Ageing Res Rev. 2015;22: 39-57. https://doi.org/10.1016/j.arr.2015.04.006.

47. Meshel DS, McGlynn RP. Intergenerational contact, attitudes, and stereotypes of adolescents and older people. Educ Gerontol. 2004;30:45779. https://doi.org/10.1080/03601270490445078.

48. Lynott PP, Merola PR. Improving the attitudes of 4th graders toward older people through a multidimensional intergenerational program. Educ Gerontol. 2007:33:63-74. https://doi.org/10.1080/03601270600864041.

49. Chorn Dunham C, Casadonte D. Children's attitudes and classroom interaction in an intergenerational education program. Educ Gerontol. 2009; 35:453-64. https://doi.org/10.1080/03601270802605473.

50. Gaggioli A, Morganti L, Bonfiglio S, Scaratti C, Cipresso P, Serino S, et al. Intergenerational group reminiscence: a potentially effective intervention to enhance elderly psychosocial wellbeing and to improve children's perception of aging. Educ Gerontol. 2014;40:486-98. https://doi.org/10.1080/ 03601277.2013.844042.

51. Gamliel T, Gabay N. Knowledge exchange, social interactions, and empowerment in an intergenerational technology program at school. Educ Gerontol. 2014;40:597-617. https://doi.org/10.1080/03601277.2013.863097.

52. Jarrott SE. Brief: survey of shared site intergenerational programs. 2019. https://www.gu.org/app/uploads/2019/01/Intergenerational-Brief-SharedSite-Survey-Report.pdf. Accessed 22 Dec 2020.

53. Ayala JS, Hewson JA, Bray D, Jones G, Hartley D. Intergenerational programs: perspectives of service providers in one Canadian city. J Intergener Relatsh. 2007:5:45-60. https://doi.org/10.1300/J194v05n02_04.

54. Niigata City. Chanoma no gakkou. 2019. https://www.city.niigata.lg.jp/smph/ iryo/korei/chiikihokatsucare/chanomanogakkou.html. Accessed 4 Sep 2020

55. Niigata City. Chuo-ku Chiiki no Chanoma. 2017. https://www.city.niigata.lg. jp/chuo/torikumi/jichikyo/kaigi_kaisai/h29kaigi_chuo/dai12kaijichikyo.files/ shiryogi1-2-1.pdf. Accessed 4 Sep 2020.

\section{Publisher's Note}

Springer Nature remains neutral with regard to jurisdictional claims in published maps and institutional affiliations.

Ready to submit your research? Choose BMC and benefit from

- fast, convenient online submission

- thorough peer review by experienced researchers in your field

- rapid publication on acceptance

- support for research data, including large and complex data types

- gold Open Access which fosters wider collaboration and increased citations

- maximum visibility for your research: over $100 \mathrm{M}$ website views per year

At $\mathrm{BMC}$, research is always in progress.

Learn more biomedcentral.com/submissions 